\title{
CONCEPTS
}

\section{Contact Dermatitis From Eriodictyon parryi: A Novel Cause of Contact Dermatitis in California}

\author{
Christopher D. Czaplicki, BS \\ From the Keck School of Medicine of the University of Southern California, Los Angeles, CA.
}

\begin{abstract}
Allergic contact dermatitis caused by Eriodictyon parryi, better known as poodle-dog bush, is a growing cause of contact dermatitis in California. Blooming after a large fire, E parryi is a threat to reforestation workers as well as countless outdoor enthusiasts across the state. This paper focuses on the epidemiology, identification, immunochemistry, pathophysiology, prevention, and treatment of contact dermatitis from this little-researched plant.
\end{abstract}

Key words: Eriodictyon parryi, Turricula parryi, poodle-dog bush, contact dermatitis

\section{Introduction}

In the study of plant-induced contact dermatitis, the majority of publications focus on the genus of Toxicodendron, specifically poison ivy, poison oak, and poison sumac. ${ }^{1,2}$ The ability to identify and avoid these species has long been a cornerstone in preventive wilderness medicine and a valuable skill for any outdoor and wilderness enthusiast. Because these plants have historically accounted for the majority of plant-induced contact dermatitis in the United States, other, less common plants have been largely ignored. However, with a recent outbreak of fires across the western United States, a new threat has emerged that most are unaware of-Eriodictyon parryi, better known as the poodle-dog bush.

E parryi is a fire chaser, sprouting the spring after a large disturbance, most commonly forest fires and landslides. ${ }^{3}$ The population quickly takes hold and expands, and it can take more than 10 years for the poodle-dog bush to be outcompeted by other plant species. A native species of California, the poodle-dog bush has been found throughout the state at elevations of 1000 to 2300 m, including the High Sierra Nevada, San Joaquin Valley, the Transverse Ranges, islands of the South Coast, and Desert Mountains including the Panamint Mountains of Death Valley. Although there have been no documented cases of E parryi outside of California in the continental United States, it has been found throughout

Corresponding author: Christopher D. Czaplicki, BS, $1800 \mathrm{~N}$ New Hampshire Avenue 201, Los Angeles, CA 90027 (e-mail: czaplick@usc. edu). the mountains of Baja California in Mexico. Currently, the highest concentration appears to be in the San Gabriel Mountains of Southern California within the burn area of the 2009 Station Fire. Burning 160,557 acres, the Station Fire is the 10th largest fire in modern California history. ${ }^{4}$ Within this burn area are hundreds of miles of trails in the Angeles National Forest, including roughly 50 miles of the Pacific Crest Trail.

\section{Plant Biology and Identification}

Despite the somewhat comical name, the poodle-dog bush, or common Turricula, has a bite just as bad as its bark. Armed with sticky, glandular hairs coated with irritating prenylated phenolics, contact with the poodledog bush causes a blistering rash in a manner similar to plants of the Toxicodendron genus. ${ }^{3,5}$ Extraction studies of poodle-dog bush glandular secretions have demonstrated that at least 3 unique compounds are capable of inducing contact dermatitis in guinea pig models. ${ }^{6} \mathrm{Al}-$ though the guinea pig studies have shown that poodledog bush extract is only $1 \%$ as potent as poison ivy, 170 $\mu \mathrm{g}$ vs $1.6 \mu \mathrm{g}$ to cause a positive reaction, these doses are greatly exceeded with each contact, making these small values of academic rather than clinical interest. Interestingly, aside from the ubiquitous and innocent ubiquinones and plastoquinones, allergic prenylated phenols, like those in poodle-dog bush extract, are only found in marine organisms, including seaweed, urochordates, and several species of sponge. 


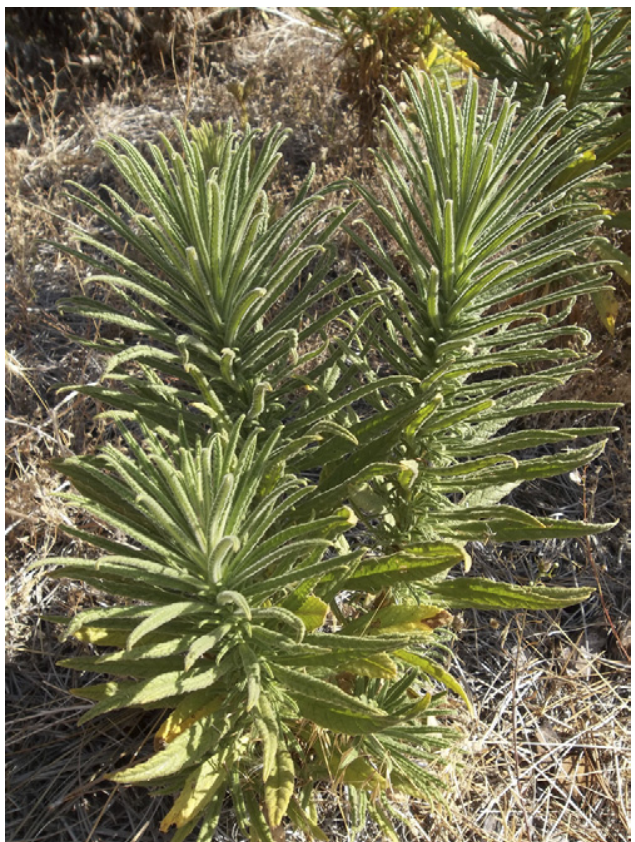

Figure 1. Poodle-dog bush (Eriodictyon parryi) has a dense leafy base with several branching stalks. The leaves are simple, cauline, with lanceolate blades measuring from 4 to $30 \mathrm{~cm}$, and covered with sticky, glandular hairs.

As with other environmental allergens, guinea pig studies have suggested an initial exposure is required for the delayed hypersensitivity reaction to occur. ${ }^{6}$ Anecdotally, however, many hikers have returned with a rash on their first known exposure, suggesting a possible prior unrecognized exposure to poodle-dog bush or to a crossreactive allergen. One notable example included several law enforcement officials working at a crime scene in Angeles National Forest. ${ }^{7}$ Completely immersed in poodle-dog bush for several hours, they exhibited an extremely severe rash that kept them out of work for several weeks.

Eriodictyon parryi, also classified as Turricula parryi, is a member of the Hydrophyllaceae family, and is closely related to the Pacific Waterleaf and forget-menot. ${ }^{8}$ Typically standing from 1 to $3 \mathrm{~m}$ tall, the poodledog bush has a dense, leafy base with several branching stalks. ${ }^{3}$ The leaves are simple, cauline, with lanceolate blades measuring from 4 to $30 \mathrm{~cm}$ (Figure 1). Flowering from June to August, the lavender-colored flowers are funnel-shaped and have been easily mistaken for the nonallergenic lupine (Figure 2). The beauty of these flowers adds an extra danger, as flower hunters pick them to bring home, and hikers often come in close contact with these types of plants. ${ }^{7}$ The poodle-dog bush has been described as ill-scented, having a rank, powerful odor that may serve as a strong aid in identification.
Because of the sometimes overwhelming smell, along with its irritant properties, E parryi is not cultivated domestically, although Native Americans did use infusions of the leaves to treat rheumatism. ${ }^{9,10}$

\section{Prevention}

Avoiding contact with poodle-dog bush is the only known tactic to preventing contact dermatitis. Taking extra care when entering any burn area is paramount, and correct identification of the plant can help avoid troublesome patches. E parryi is taller than most other flowering plants in California, and is typically accompanied by a strong odor. ${ }^{3}$ However, take care not to rely on any one particular feature of the plant, as they are still allergenic when not in bloom (and therefore not as odorous).

If contact cannot be avoided, wearing protective layers is the next best option. Topical barrier preparations have been investigated for various members of the Toxicodendron family; however, there is currently no research testing topical barrier efficacy for E parryi. ${ }^{11,12}$

Should you come into contact with $E$ parryi, best evidence suggests washing the affected area with soap and water. Any clothes suspected to be contaminated should not be touched, and should be washed when possible. Because the allergic prenylated phenols from poodle-dog bush have been isolated with acetone, it is reasonable to believe that other organic solvents may be effective at removing poodle-dog bush allergens from the skin. ${ }^{5}$ However, there is currently no research examining potential organic solvents for use in the field for removal of the prenylated phenols of E parryi. Additionally, although allergens from the Toxicodendron family

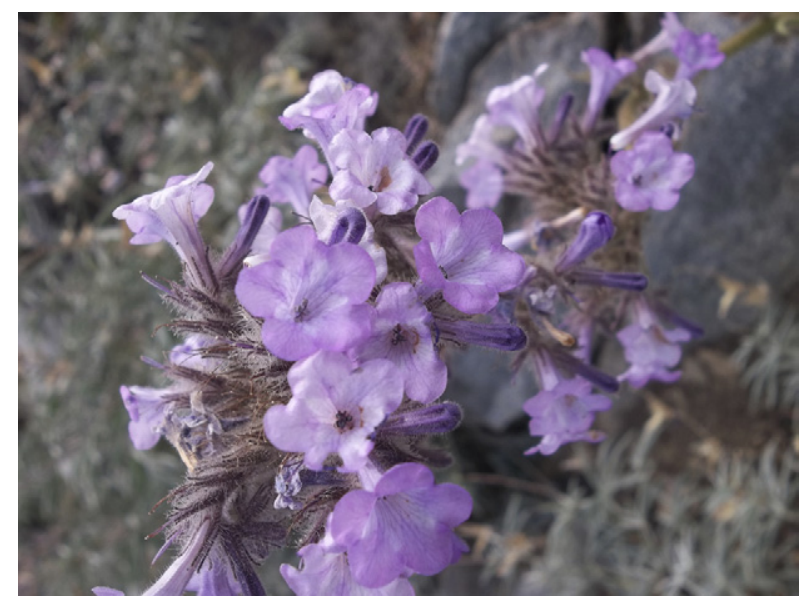

Figure 2. Poodle-dog bush (Eriodictyon parryi) has lavender-colored funnel-shaped flowers that are easily mistaken for various species of lupine. Poodle-dog bush typically blooms from June to August, giving off a strong odor during that time. 


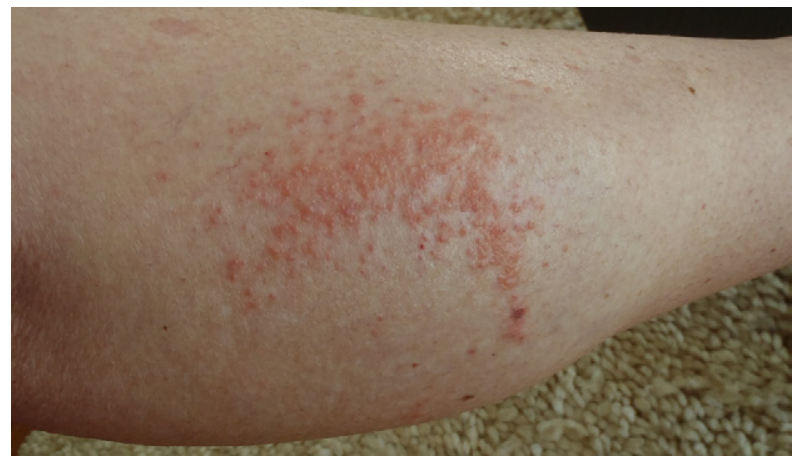

Figure 3. The characteristic patch of small, erythematous vesicles on the mid-calf several days after contact with Eriodictyon parryi while hiking in Angeles National Forest. Photo courtesy of Dawn Jackson.

have been found to bind to the stratum corneum in less than 10 minutes, no corresponding research has been performed for E parryi. ${ }^{13}$

\section{Presentation}

Although the offending compounds of E parryi are quite different from those of Toxicodendron, the mechanism behind the rash formation is the same: a type IV hypersensitivity reaction in previously sensitized individuals. ${ }^{13,14}$ Thus, exposed individuals typically present within 24 to 48 hours after exposure with streaky arrangements of papules, vesicles, and bullae (Figure 3). ${ }^{15}$ These are completely devoid of antigenic potential. Should the individual have made contact with any mucous membranes, including the mouth, anus, or genitals, the edema may be severe locally.

\section{Management}

Treatment and management of contact dermatitis from $E$ parryi is identical to that of the Toxicodendron plants, as the rash occurs by the same hypersensitivity reaction, and ultimately depends on the severity of the rash. Most cases are self-limiting and last 1 to 3 weeks. ${ }^{1}$ Local symptoms can be treated with cold compresses using water or diluted aluminum acetate, or calamine lotions. ${ }^{15}$ In addition, lukewarm baths with baking soda or colloidal oatmeal, such as Aveeno, may provide relief. Topical anesthetics should be selected carefully, as benzoic acid ester agents such as benzocaine may act as sensitizers and should be avoided. ${ }^{16}$ Other classes of topical anesthetics including amide agents such as lidocaine as well as pramoxine (Sarna Sensitive, $1 \%$; Itch-X, 1\%) have been shown to be more effective with a lower likelihood of acting as a sensitizing agent. ${ }^{17,18}$ Cross-reactivity between classes is still possible, and patients should be advised to discontinue the topical anesthetic should the lesion get worse. ${ }^{19}$ There is little evidence to support the use of topical antihistamines in treatment, as the itching is not histamine mediated. ${ }^{20}$ Oral antihistamines, however, can be used for their sedative side effects.

In moderate to severe cases corticosteroids may be used. Topical corticosteroids should be used early in the treatment, before the vesicles form, to decrease pruritus and erythema. Occlusive creams should be avoided if the rash is weeping. ${ }^{15}$ Moderate- to high-potency topical steroids, such as triamcinolone $0.1 \%$ (Kenalog, Aristocort) or clobetasol $0.05 \%$ (Temovate), are commonly used for localized lesions for brief periods of 2 weeks or less. ${ }^{21}$ However, in areas with thinner skin, including the face, eyelids, groin, axillae, and inframammary folds, lower-potency topical steroids, such as desonide ointment (DesOwen), are more appropriate to avoid skin atrophy and adrenal suppression through rapid skin absorption. If the patient is experiencing systemic symptoms, oral prednisone $(1 \mathrm{mg} / \mathrm{kg})$ may be used, tapering the dosage over 2 to 3 weeks. ${ }^{15}$ This tactic may also be effective if the rash covers an extensive area of the skin. ${ }^{21}$ If the dose is too low or the course too short, steroid-resistant rebound flares may occur. ${ }^{22,23}$

\section{Conclusions}

Although exposure to Toxicodendron species will always remain high on the differential for plant contact dermatitis, it is important to consider E parryi for patients across California, particularly those near recent burn areas. Experienced hikers may attribute their contact dermatitis to poison oak, which has an overlapping growth area, and not realize the true nature of their rash. Thus, education of our patients and the general public is pivotal if we are to prevent these cases of contact dermatitis. Although the National Forest Service of Angeles National Forest has started placing warnings in select trailheads and picnic areas, it simply is not enough for the hundreds of thousands of visitors the forest receives each year. Only through a greater public outreach and education can poodle-dog bush be truly muzzled.

\section{Acknowledgments}

The author has no financial relationships with commercial entities that may pose a conflict of interest.

\section{References}

1. Gladman AC. Toxicodendron dermatitis: poison ivy, oak, and sumac. Wilderness Environ Med. 2006;17:120-128. 
2. Boelman DJ. Emergency: treating poison ivy, oak, and sumac. Am J Nurs. 2010;110:49-52.

3. Hickman JC, ed. The Jepson Manual: Higher Plants of California. Berkeley, CA: University of California Press; 1993.

4. US Government Accountability Office. Station Fire: Forest Service's Response Offers Potential Lessons for Future Wildland Fire Management. Washington, DC: U.S. Government Accountability Office. Available at http:// www.gao.gov/products/GAO-12-155. Accessed February 18, 2013.

5. Reynolds GW, Proksch P, Rodriguez E. Prenylated phenolics that cause contact dermatitis from glandular trichomes of Turricula parryi. Planta Med. 1985;51: 494-498.

6. Reynolds GW, Epstein WL, Rodriguez E. Unusual contact allergens from plants in the family Hydrophyllaceae. Contact Dermatitis. 1986;14:39-44.

7. Becerra H. Beware of poisonous poodle-dog bush, officials warn. L.A. Times, July 24, 2011. Available at: http://articles. latimes.com/2011/jul/24/local/la-me-poodle-dog-bush20110724. Accessed January 24, 2013.

8. Ferguson DM. Phylogenetic analysis and relationships in Hydrophyllaceae based on ndhF sequence data. Systematic Botany. 1998;23:253-268.

9. Sparkman PS. The Culture of the Luiseño Indians. University of California Publications in American Archaeology and Ethnology. Berkeley, CA: The University Press; 1908: 187-234.

10. Zigmond ML. Kawaiisu Mythology: An Oral Tradition of South-Central California. Ballena Press Anthropological Papers. Socorro, NM: Ballena Press; 1980.

11. Grevelink SA, Murrell DF, Olsen EA. Effectiveness of various barrier preparations in preventing and/or ameliorating experimentally produced Toxicodendron dermatitis. J Am Acad Dermatol. 1992;27(2 Pt 1):182-188.
12. Scott MJ, Heumann MA, DeBruyckere DM, Brundage TW, Kohn MA. The feasibility of using skin protectant products and education to prevent poison oak. Wilderness Environ Med. 2002;13:206-208.

13. Fisher AA. Poison ivy/oak dermatitis. Part I: preventionsoap and water, topical barriers, hyposensitization. Cutis. 1996;57:384-386.

14. Fisher AA. Poison ivy/oak/sumac. Part II: specific features. Cutis. 1996;58:22-24.

15. Lee NP, Arriola ER. Poison ivy, oak, and sumac dermatitis. West J Med. 1999;171:354-355.

16. Eggleston ST, Lush LW. Understanding allergic reactions to local anesthetics. Ann Pharmacother. 1996;30: 851-857.

17. Yosipovitch G, Maibach HI. Effect of topical pramoxine on experimentally induced pruritus in humans. J Am Acad Dermatol. 1997;37(2 Pt 1):278-280.

18. Shuttleworth D, Hill S, Marks R, Connelly DM. Relief of experimentally induced pruritus with a novel eutectic mixture of local anaesthetic agents. Br J Dermatol. 1988;119: 535-540.

19. García F, Iparraguirre A, Blanco J, et al. Contact dermatitis from prilocaine with cross-sensitivity to pramocaine and bupivacaine. Contact Dermatitis. 2007;56:120-121.

20. Yosipovitch G, Fleischer A. Itch associated with skin disease: advances in pathophysiology and emerging therapies. Am J Clin Dermatol. 2003;4:617-622.

21. American Academy of Allergy, Asthma and Immunology; American College of Allergy, Asthma and Immunology. Contact dermatitis: a practice parameter. Ann Allergy Asthma Immunol. 2006;97(3 suppl 2):S1-S38.

22. Wooldridge WE. Acute allergic contact dermatitis. How to manage severe cases. Postgrad Med. 1990;87:221-224.

23. Ives TJ, Tepper RS. Failure of a tapering dose of oral methylprednisolone to treat reactions to poison ivy. JAMA. 1991;266:1362. 